\title{
A Cross-Cultural Comparison of Middle-Class Meanings of Money in India and South Korea: An Abstract
}

\author{
Altaf Merchant, Gregory Rose, Sunmee Choi, Drew Martin, and Mohit Gour
}

\begin{abstract}
Little research exists that qualitatively and systematically examines the rich symbolic meanings of money across cultures. To what extent are symbolic money meanings universal? What roles do economic development and sociocultural differences play in shaping the symbolic meanings and attitudes associated with money? Prior research in the USA documents the interaction between societal changes, money meanings, and family dynamics and demonstrates that economic changes impact attitudes about money (Commuri \& Gentry, 2005; Zeiler, 1989). This study builds on this research by examining differences in symbolic money meanings across two nations, India and Korea, at different stages of economic development. Qualitative analysis documents, assesses, and contrasts the rich, symbolic meanings of money for middle-class individuals in these nations.
\end{abstract}

References Available Upon Request

\footnotetext{
A. Merchant $(\bowtie) \cdot G$. Rose

University of Washington, Tacoma, WA, USA

e-mail:altafm@uw.edu; rosegm@uw.edu

S. Choi

Yonsei University, Seoul, South Korea

e-mail: sc128@yonsei.ac.kr

D. Martin

University of Hawaii, Hilo, HI, USA

e-mail: drmartin@hawaii.edu

M. Gour

Issues and Answers Network Inc, Virginia Beach, VA, USA

e-mail:mgour@issans.com
} 